\title{
IT Infrastructure Support for the Implementation of the Balanced-Empirical Mechanism of the Strategic Analysis and Forecasting System for Copper Industry Enterprises
}

\author{
Oleg Bazhenov \\ Department of Accounting, Analysis and Audit \\ Ural Federal University named after the first President of \\ Russia B. N. Yeltsin \\ Ekaterinburg, Russia \\ o.v.bazhenov@urfu.ru
}

\author{
Oxana Sukhova \\ Department of Enterprise Economics, \\ Ural State University of Economics \\ Ekaterinburg, Russia \\ o.v.bazhenov@urfu.ru
}

\begin{abstract}
The article presents the authors' vision of IT support for the implementation of the balanced-empirical mechanism of the strategic analysis and forecasting system for copper industry enterprises.
\end{abstract}

For this purpose, the authors consistently address the following issues:

1) we introduce and briefly describe the concept of the balanced-empirical mechanism;

2) we present the elemental structure of the balancedempirical mechanism and a flowchart of its implementation;

3) we suggest using the balanced-empirical mechanism of the strategic analysis and forecasting system for the activity of copper industry enterprises to substantiate the priorities of strategic programs.

4) we justify the use of a single information space based on the corporate portal platform as a basis for the automation of strategic analysis and forecasting system for copper industry enterprises;

5) the authors present and briefly describe their vision of the corporate portal structure as part of the automation of the strategic analysis and forecasting system for the copper industry;

6) we suggest a process automation flowchart of strategic analysis and forecasting for the activity of copper industry enterprises;

The study used methods of comparative analysis and synthesis of information obtained from various sources.

The authors present their vision of IT support of the strategic analysis and forecasting system for the activity of copper industry enterprises, implemented through a balanced-empirical mechanism. Wherein, the IT infrastructure is based on a single information space (a corporate portal) as the structured basis of an enterprise and the calculations.

Provisions and conclusions of the presented work can be applied by the management of metallurgical holdings, metallurgical clusters and separate enterprises of copper industry to mainstream the strategic analysis and forecasting approaches of the enterprises' activity, as well as by the regional executive authorities to find ways to increase the investment attractiveness of the region.

Keywords: strategic analysis and forecasting, strategic management, organizational and methodological framework of strategic analysis, system of strategic analysis and management, balanced-empirical mechanism, IT support for strategic analysis and forecasting

\section{INTRODUCTION}

Corporate governance, organized on the basis of information results of strategic analysis has become widespread in the activities of large industrial enterprises, which determines a fairly serious methodological study of theoretical and practical aspects of enterprise strategic analysis and forecasting. Thus, the issues of strategic corporate governance were considered in the works [1-6, etc.]. Analysis method application of the external economic environment was presented in works [7-11, etc.]. Methodical aspects of the internal environment analysis and the direction of use of the obtained results are presented in the following studies [12-16, etc.].

The choice of tools for implementation of the strategic analysis and forecasting system for the activity of copper industry enterprises - the balanced-empirical mechanism - is determined by the fact that balanced-empirical mechanism can be used as a tool to improve the efficiency of strategic analysis and forecasting for copper industry enterprises, providing correlation of administrative decisions with the performance of copper industry enterprises. 
external micro-environment (industry level), external meso-environment (intersectoral level), external macro-environment (state level); empirical mechanism as a system of mechanisms for strategic analysis and forecasting of activity of the copper industry enterprises, given all its characteristics (properties, relationships, parameters of functioning, etc.) and features [17].

The purpose of implementing a balanced-empirical mechanism of strategic analysis and forecasting for the activity of copper industry enterprises is to assess the current level of consolidated environment (external and internal) based on the values of key assessment indicators of domestic production environment, internal non-production environment, external micro-environment (industry level), external mesoenvironment (intersectoral level), external macro-environment (state level) and additional data of the copper industry enterprise development strategy, presented as a list of planned strategic programs and their estimated implementation costs.

The balanced-empirical mechanism of strategic analysis and forecasting for the activity of copper industry enterprises must include the following elements:

- formulas for calculating indicators included in the balanced system of internal environment assessment;

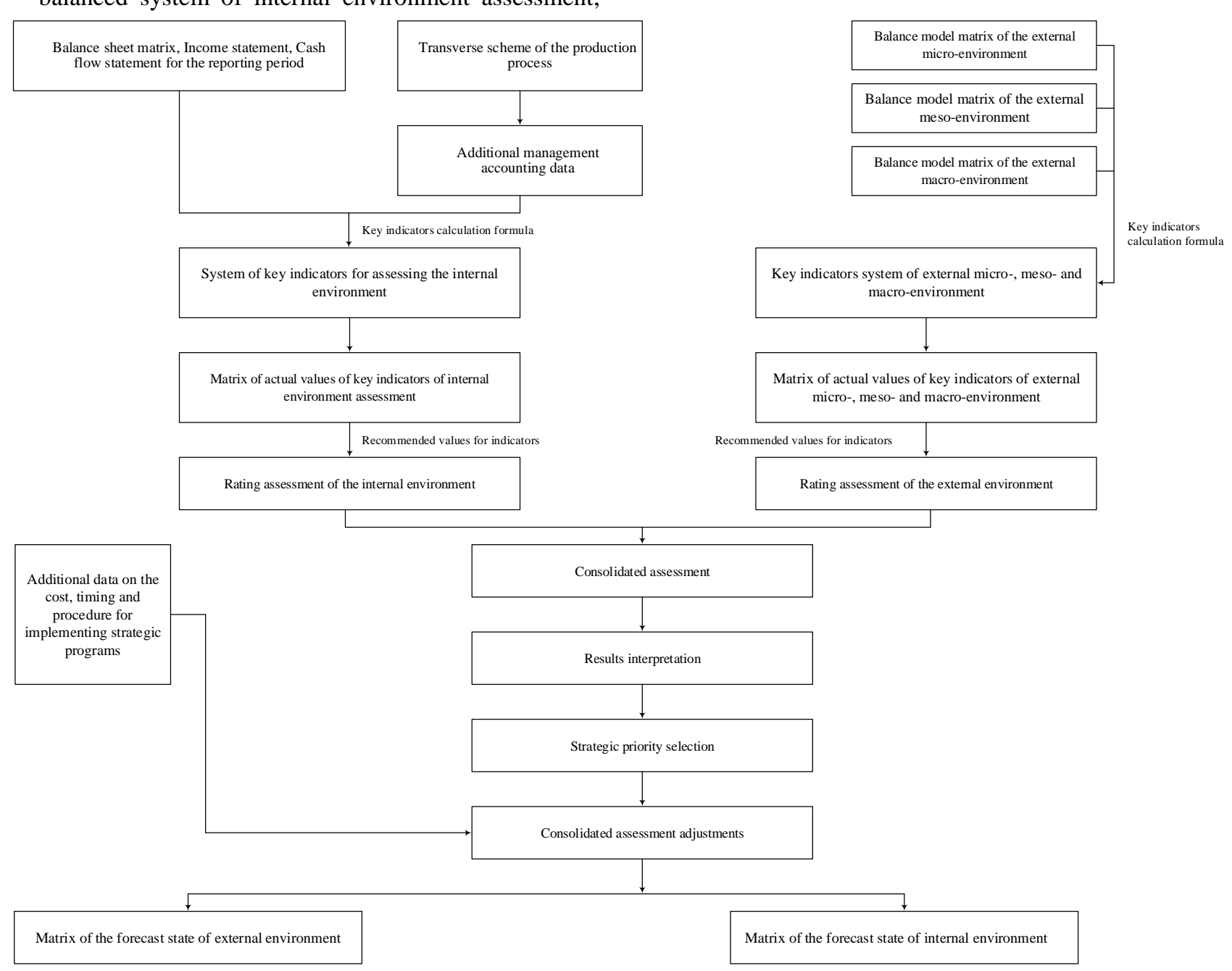

Fig. 1. Flowchart of the balanced-empirical mechanism of strategic analysis and forecasting for activity of the copper industry enterprises
- balance sheet matrix, income statement, cash flow statement for the reporting period;

- balance model matrix of the external microenvironment (industry level), external mesoenvironment (intersectoral level), external macroenvironment (state level) with the estimated indicator values;

- transverse scheme of production activity with estimated indicator values;

- additional management accounting data and data on the cost, timing and implementation of strategic programs;

- actual indicator values matrix of balanced assessment system of external and internal environment of copper industry enterprises, calculated based on current data;

- forecast state matrix of external and internal environment of an enterprise;
. 
The main purpose of the information portal of copper

- recommended values of the balanced system indicators formed in the context of the main strategic areas [18].

\section{RESEARCH METHOD}

The study used methods of comparative analysis and synthesis of information obtained from various sources.

\section{RESULTS AND DISCUSSION}

The implementation flowchart of the balanced-empirical mechanism of strategic analysis and forecasting for the copper industry can be presented as follows (Figure 1).

Developed flowchart of the balanced-empirical mechanism of strategic analysis and forecasting for activity of the copper industry enterprises can be used in the following cases:

- in the development of specialized software required to automate the implementation of strategic analysis and forecasting system for copper industry enterprises;

- for adjusting the existing corporate business processes responsible for the analytical support of copper industry enterprises;

- for adjusting the existing internal document flow related to the analytical support of copper industry enterprises.

The balanced-empirical mechanism of strategic analysis and forecasting for copper industry enterprises activity, proposed by the authors, is rather complicated in terms of calculations, which explains the need for its automation.

The authors advice to implement the automation of strategic analysis and forecasting system for the activity of copper industry enterprises based on a single information space.

Thus, a single information space is the interaction system of enterprise workers at the information level, allowing to integrate appendices, databases, services, etc. in a single shell with the access to all software products of an enterprise.

Single information space makes it possible to:

- access the information services without being bound to the workplace;

- accumulate and group initial analytical data;

- build hierarchical systems enabling managerial decisions at different levels of an enterprise [19].

The authors suggest using the corporate portal of the copper industry as a platform for implementing a single information space. The corporate portal makes it possible to integrate a set of existing applications and databases into a single information environment, which allows to: improve the organization of production activity, to increase the efficiency of administrative and financial-economic decision-making, provide communication between separate production stages (structural subdivisions) of copper industry enterprises, and ensure a synergetic effect from the joint work of users. industry to cover the provisions of this clause is to maximize the satisfaction of managers and analytical specialists' needs through the use of modern information technology in the following areas:

- accumulation of raw analytical data;

- grouping of analytical data and their initial processing;

- conducting analytical calculations and assessments;

- interpretation of the calculated material;

- construction of graphical models based on calculated data;

- structuring and presentation of information on different levels of the management hierarchy of an enterprise;

- providing control functions.

Thus, the corporate portal can be presented as follows (Figure 2).

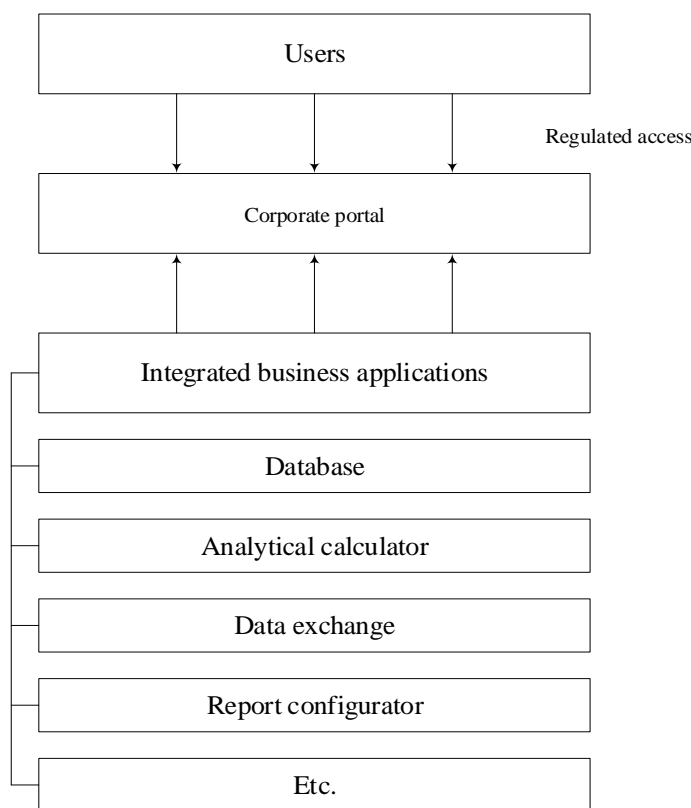

Fig. 2. Scheme of a corporate portal for the copper industry enterprises (compiled by the authors)

Therefore, a single information space formed based on the corporate portal provides:

- personalized user access to information;

- single point of user authentication;

- possibility of using a wide range of specialized software;

- possibility of creating corporate databases;

- personalization of the data received by a particular user 


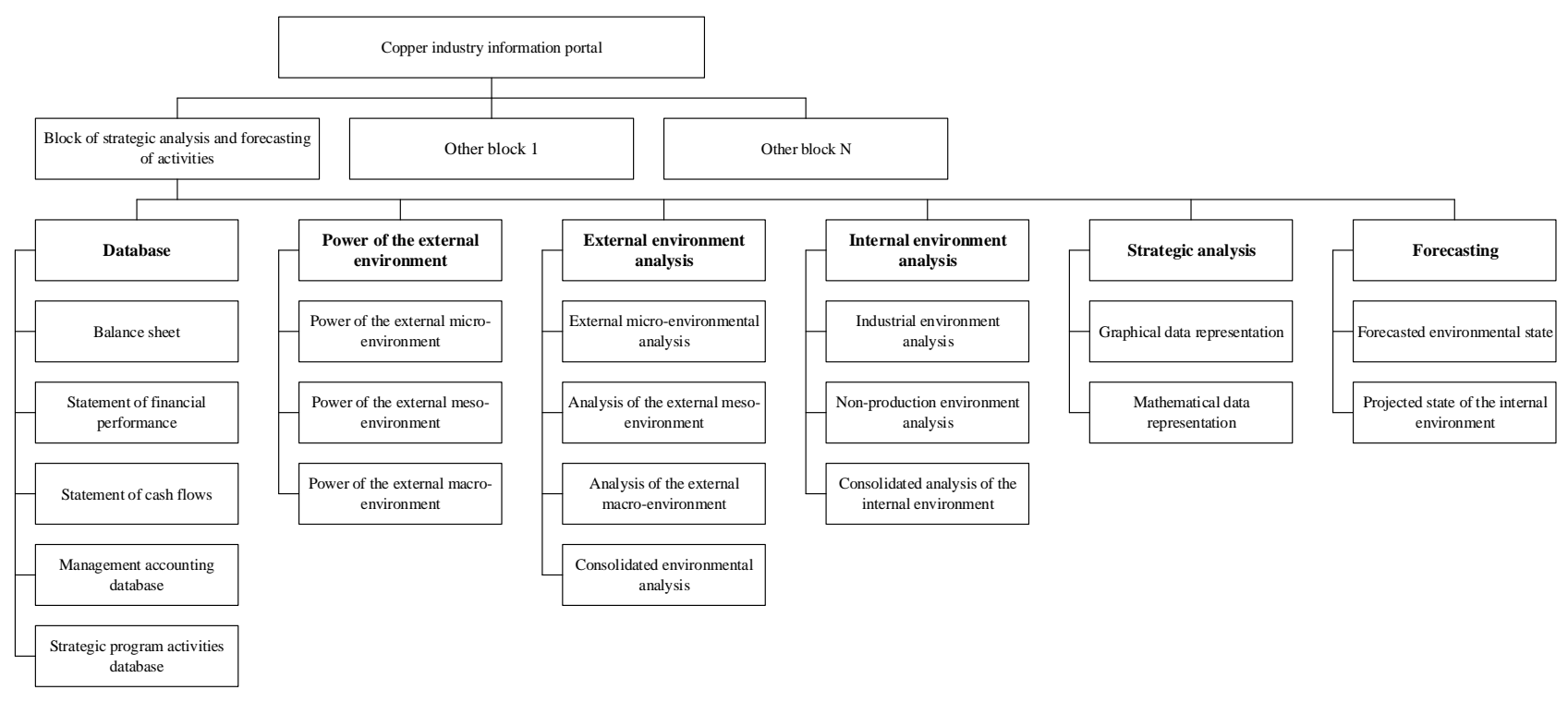

Fig 3. Structure of the corporate portal to ensure the automation of strategic analysis and forecasting system for the activities of copper industry enterprises [20]

- development of management solutions through integration of data received from various databases, systems, applications and analytical procedures and presenting information in a visual form;

- corporate communication;

- possibility of correlation with external systems based on information technologies, etc.
Let us further consider the automation procedure of strategic analysis and forecasting system for the activity of copper industry enterprises trough the use of a single information space based on a corporate information portal.

At the same time, the automated system must provide realization of the balanced-empirical mechanism of the strategic analysis and forecasting for the activity of copper

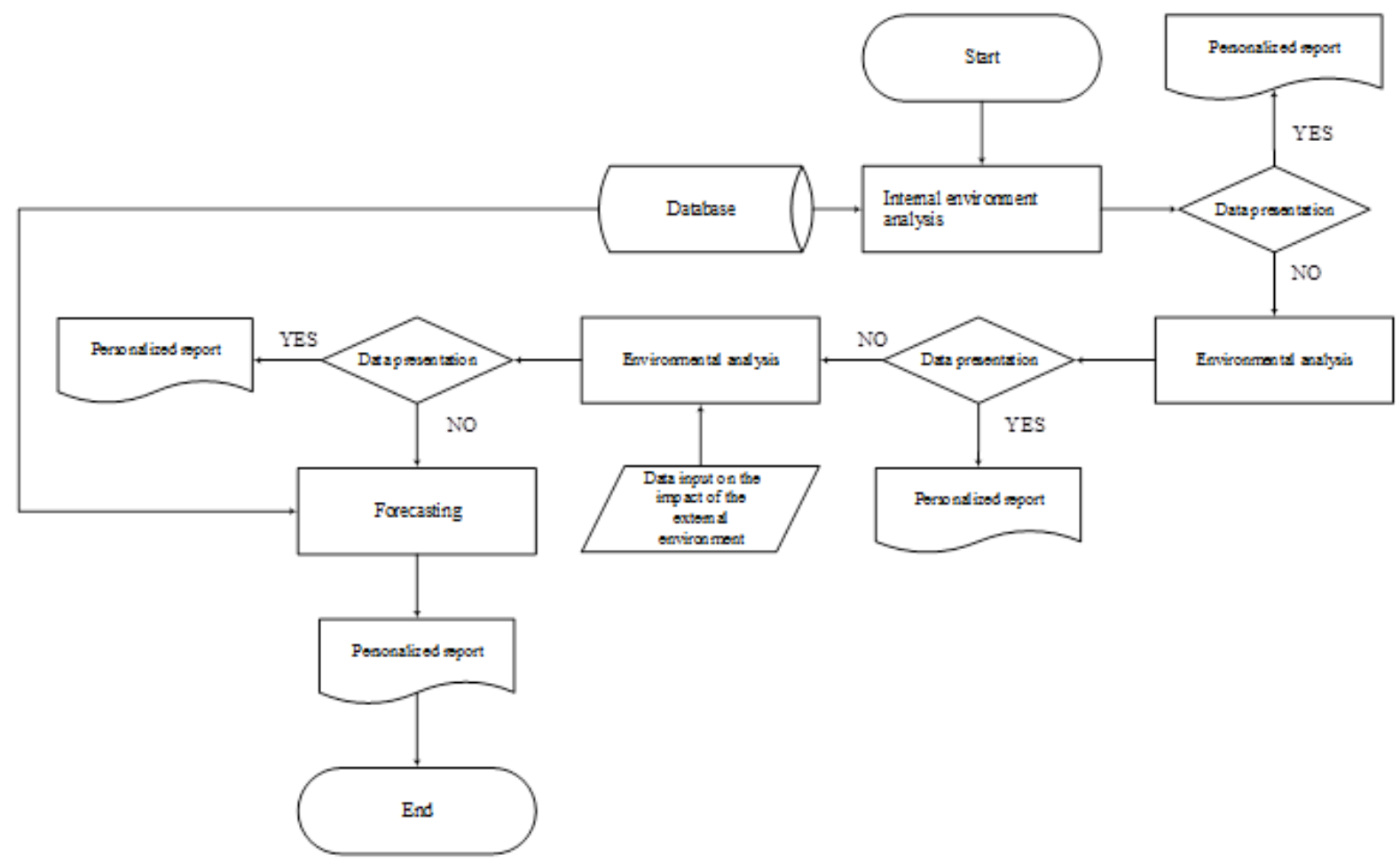

Fig 4. Flowchart of the automation process of strategic analysis and forecasting for the activity of copper industry enterprises 
[4] Z. Meimankulova, S. Umirzakov, "Strategic management and development market of dairy products on the basis of increasing domestic and innovation production," Journal of Applied Economic Sciences, vol. 13(7), 2018, pp. 1984-2003.

The authors' vision of the corporate portal content as part of the automation of strategic analysis and forecasting system for the copper industry enterprises can be presented as follows (Figure 3).

The flowchart of the automation process of strategic analysis and forecasting for the activity of copper industry enterprises can be presented as follows (Figure 4).

\section{CONCLUSION}

Therefore, this study examines the automation procedure of strategic analysis and forecasting system for the activity of copper industry enterprises. Since the beginning of project implementation the following project results were achieved:

- the study presents a balanced-empirical mechanism of strategic analysis and forecasting for the activity of copper industry enterprises;

- the authors suggest using the balanced-empirical mechanism of strategic analysis and forecasting for the activity of copper industry enterprises to substantiate the areas of strategic programs implementation;

- a single information space, formed on the platform of the corporate portal, was justified as a basis for the automation of strategic analysis and forecasting system for the activity of copper industry enterprises;

- the authors present and briefly describe their vision of the corporate portal structure within the framework of ensuring automation of strategic analysis and forecasting for the activity of copper industry enterprises;

- The study presents a flowchart of the automation of strategic analysis and forecasting for the activity of copper industry enterprisesr.

\section{ACKNOWLEDGMENTS}

The work was supported by Government of the Russian Federation, project № MK-914.2019.6.

\section{REFERENCES}

[1] E.P. Vieira, J.O. Sausen, M.L. Kelm, "Strategic cost management: a model proposal for the machine industry and agricultural implements," Custos e Agronegocio, vol. 14, 2018, pp. 332-360.

[2] A.F. McKenny, J.C. Short, D.J. Ketchen, "Strategic entrepreneurial orientation: Configurations, performance, and the effects of industry and time," Strategic Entrepreneurship Journal, vol. 12(4), 2018, pp. 504-521.

[3] J. Dobrovič, M. Urbański, P. Gallo, E. Benková, V. Čabinová, "Balanced scorecard concept as a tool of strategic management and its usage in the construction industry," Polish Journal of Management Studies, vol. 18(2), 2018, pp. 59-72.

5] E.P. Vieira, J.O. Sausen, M.L. Kelm, "Strategic cost management: A model proposal for the agricultural machinery and implements industry," Custos e Agronegocio, vol. 14, 2018, pp. 332-360.

[6] O. Kalchenko, S. Evseeva, K. Plis, O. Evseeva, "Predictive analytics in goals' achievements of the strategy of economic and social development of St. Petersburg until 2030," Proceedings of the 33rd International Business Information Management Association Conference, IBIMA 2019: Education Excellence and Innovation Management through Vision 2020, 2019, pp. 8789-8797.

[7] Q. Wu, W. Wang, "Dynamic growth of technological innovation capability of manufacturing enterprises from the perspective of open innovation on evaluation," 5th International Conference on Industrial Economics System and Industrial Security Engineering, IEIS 2018, 2018, p. 8598021.

[8] M. Osmani, A. Kambo, M. Andoni, "Dynamic interactions between major macroeconomic aggregates in Albania. A vector autoregression approach," Journal of Applied Economic Sciences, vol. 13(8), 2018, pp. 2196-2215.

[9] S.S. Ramanayake, C.S. Wijetunga, "Sri Lanka's Labour Migration Trends, Remittances and Economic Growth," South Asia Research, vol. 38, 2018, pp. 61-81.

[10] M.A. Izmailova, N.S. Khoroshavina, N.V. Rebrikova, O.V. Kolesnikova, O.A. Shalnova, "Major factors of achievement of quality of corporate management in the Russian medium-sized companies," Quality - Access to Success, vol. 19(166), 2018, pp. 72-79.

[11] D. Doulos, O. Katsaitis, G. Zombanakis, "Analysis of Asymmetric Responses of the External Sector to Economic Growth," International Advances in Economic Research, vol. 24(3), 2018, pp. 301-302.

[12] J. Sinthupundaja, N. Chiadamrong, Y. Kohda, "Internal capabilities, external cooperation and proactive CSR on financial performance," Service Industries Journal, vol. 39(15-16), 2019, pp. 1099-1122.

[13] I. Lončarski, L. Vidovič, "Sorting out the financials: Making economic sense out of statistical factors," Finance Research Letters, vol. 31, 2019 , pp. 110-118.

[14] J. Wildberg, B. Möhring, "Empirical analysis of the economic effect of tree species diversity based on the results of a forest accountancy data network," Forest Policy and Economics, vol. 109, 2019, p.101982.

[15] S. Lan, C. Yang, M.L. Tseng, "Corporate sustainability on causal financial efficiency model in a hierarchical structure under uncertainties," Journal of Cleaner Production, vol. 237, 2019, p. 117769 .

[16] T. Schaubroeck, C. Petucco, E. Benetto, "Evaluate impact also per stakeholder in sustainability assessment, especially for financial analysis of circular economy initiatives," Resources, Conservation and Recycling, vol. 150, 2019, p. 104411.

[17] O.V. Bazhenov, "Balanced-empirical mechanism - an instrumental basis for strategic analysis and forecasting of the activities of enterprises of the copper industry," Management Accounting, vol. 5, 2018, pp. 28-36.

[18] O.V. Bazhenov, "Development and implementation of a balanced empirical mechanism for strategic analysis and forecasting of the activity of enterprises of the copper industry," Economics and Entrepreneurship, vol. 5-2(46), 2014, pp. 495-500.

[19] A.A. Kovalchik, D.G. Vysokinsky, A.V. Kritsky, Unified information space of water supply and sewage enterprises, 2013.

[20] O.V. Bazhenov, Theoretical and methodological aspects of strategic analysis and forecasting of the enterprise, 2015. 